\title{
Pensar entre épocas: escrituras de vidas y transformación subjetiva en el Chile post-Pinochet
}

\author{
Thinking between Eras: Life Writing and Subjective \\ Transformation in Post-Pinochet Chile \\ Pensar entre épocas: escritas de vidas e transformação \\ subjetiva no Chile pós-Pinochet
}

\section{Michael J. Lazzara}

UNIVERSITY OF CALIFORNIA, DAVIS, ESTADOS UNIDOS

Profesor asociado de literatura y estudios culturales latinoamericanos en la Universidad de California, Davis. PhD Princeton University. Es autor de Luz Arce and Pinochet's Chile: Testimony in the Aftermath of State Violence (Palgrave Macmillan, 2011), Luz Arce: después del infierno (Cuarto Propio, 2008), Prismas de la memoria: narración y trauma en la transición chilena (Cuarto Propio, 2007), Chile in Transition: The Poetics and Politics of Memory (University Press of Florida, 2006), Diamela Eltit: conversación en Princeton (PLAS, 2002) y Los años de silencio: conversaciones con narradores chilenos que escribieron bajo dictadura (Cuarto Propio, 2002). También ha coeditado con Vicky Unruh el libro Telling Ruins in Latin America (Palgrave Macmillan, 2009). Contacto: mjlazzara@ucdavis.edu 


\section{Resumen}

Los aniversarios de los treinta y de los cuarenta años del golpe de Estado que instaló la dictadura de Pinochet en Chile han sido acompañados por una especie de "boom" autobiográfico y memorialista. Tanto figuras políticas conocidas como exmilitantes de los sesenta y setenta han dado a conocer sus relatos de vida en formato de libros, entrevistas y películas. Este artículo examina las autorrepresentaciones de dos autobiógrafos chilenos, Max Marambio (ex-MIR) y Eugenio Tironi (ex-MAPU), que han abandonado sus posiciones radicales de izquierda convirtiéndose en lo que hoy en Chile se conoce como izquierdistas "renovados" (es decir, un izquierdismo que opera dentro de la lógica del mercado neoliberal). ¿Cómo cuentan sus vidas y justifican sus metamorfosis subjetivas? El artículo cierra con un examen del discurso de Marco Enríquez-Ominami, hijo del líder legendario del MIR (Miguel Enríquez) y dos veces candidato a la presidencia (2009 y 2013), cuya vida dramatiza tanto la problemática de la izquierda en la postdictadura como la tensión que surge al pensar entre épocas.

Palabras claves: autobiografía; Chile; ideología; memoria; transiciones a la democracia

\section{Abstract}

The thirtieth and fortieth anniversaries of General Pinochet's military coup in Chile have been accompanied by an explosion of autobiographical and memoir writing. Well-known political figures and former radical leftist militants of the 1960s and 1970s have published their life stories in book, interview, and film formats. This article examines self representations by two Chilean autobiographers, Max Marambio (ex MIR) and Eugenio Tironi (ex MAPU), who have abandoned their radicalized positions of the revolutionary era and have become what in Chile today are known as "renovated leftists", that is, leftists who embrace the neoliberal free market. How do these subjects narrate and justify their subjective metamorphoses? The article concludes with an analysis of Marco Enríquez-Ominami, the son of legendary MIR leader Miguel Enríquez and twice a candidate for the presidency (in 2009 and 2013 respectively). His life dramatizes the problems the Chilean left has faced in the postdictatorship period as well as the tensions that arise when a subject attempts to think between epochs.

Keywords: autobiography; Chile; ideology; memory; transitions to democracy

\section{Resumo}

As comemorações dos trinta e quarenta anos do golpe de Estado que instalou a ditadura de Pinochet no Chile foi acompanhada por una espécie de "boom" autobiográfico e memorialista. Tanto figuras políticas conhecidas quanto exmilitantes dos sessenta e setenta deram a conhecer seus relatos de vida em formato de livros, entrevistas e filmes. Este artigo examina as autorrepresentações de dois autobiógrafos chilenos, Max Marambio (ex-MIR) e Eugenio Tironi (ex-MAPU), que abandonaram suas posições radicais de esquerda virando para o que hoje é conhecido no Chile como esquerdistas "renovados" (ou seja, um esquerdismo que opera dentro da lógica do mercado neoliberal). Como é que eles contam suas vidas e justificam suas metamorfoses subjetivas? $\mathrm{O}$ artigo fecha com exame do discurso de Marco Enríquez-Ominami, filho do líder lendário do MIR (Miguel Enríquez) e duas vezes candidato para a presidência (2009 y 2013), cuja vida dramatiza tanto a problemática da esquerda na pós-ditadura quanto a tensão surgida ao pensar entre épocas.

Palavras-chave: autobiografia; Chile; ideologia; memória; transições para a democracia.

\section{Cómo citar este artículo:}

Lazzara, Michael J. "Pensar entre épocas: escrituras de vidas y transformación subjetiva en el Chile post-Pinochet". Cuadernos de Literatura 18.36 (2014): 166-183. http://dx.doi.org/10.11144/Javeriana.CL18-36.peev 


\section{Presentación}

La inspiración de este trabajo nace del título de un libro del ensayista argentino Nicolás Casullo - Pensar entre épocas: memoria, sujetos y crítica intelectual (2004)-, quien en ese y otros textos aborda el dilema de cómo y si es posible captar una época, la de las revoluciones y las luchas armadas de los sesenta y setenta en América Latina, desde el presente globalizado y neoliberal. Como a Beatriz Sarlo, John Beverley y otros intelectuales que han escrito en años recientes sobre el tema, a Casullo le inquieta la pregunta por el "espíritu" de una época, su verdadera cara política y social, sobre todo pensando desde un presente cuya producción cultural periodística o mediática muchas veces no parece hacer mucho más que citar ese pasado o presentarlo de una manera caricaturesca (cuando no lo ignora por completo), sin poder captar sus verdaderos sentidos. Como explica Casullo en un ensayo de 2007 titulado "Historia y memoria": "Efectivamente se impuso como historia política 'de los setenta' la anécdota, lo llamativo, lo esperpéntico, lo acusatorio, lo extremo, el testimonio recortado, los errores, lo curioso, la ignorancia de lo acontecido, lo diabolizador, el olvido [... y los] lugares comunes" (Las cuestiones 240-241). A todo esto hay que sumarle una serie de factores claves adicionales que, sin duda, tiñen los relatos presentistas sobre las revoluciones y las izquierdas - entre ellos, la derrota, los traumas sufridos, los exilios vividos y el destino de las izquierdas en un ámbito global—, factores, todos ellos, que no deben ser subestimados a la hora de meditar sobre la deshistorización de aquellos tiempos en la narrativa de la época actual.

Al mismo tiempo, distintas reflexiones teóricas (de Nelly Richard, Leonor Arfuch, Fernando Blanco y otros) han dejado en evidencia que en nuestra época memorialista estamos frente a una proliferación de narrativas en primera persona sobre el pasado reciente de muy diverso estilo, una especie de "mercado de lo confesional" del que participan biografías, autobiografías, testimonios y documentales de personajes cuyas vidas íntimas se vuelven públicas y se ponen al servicio de espectadores que desean consumirlas (Richard 300). Pero al volver público lo íntimo, como señala Arfuch, lo que casi siempre se nos narra no es una vida real, sino la "vida ejemplar" de un sujeto que se pone en escena, revelando una máscara, una ficcionalización del yo que, desplazado en el tiempo, intenta convivir consigo mismo e hilvanar una narrativa medianamente coherente, a veces balbuceando en su falta de coherencia (47). Se trata, en muchos casos, de sujetos a la deriva en el tiempo que han tenido que redefinirse y reimaginarse en una época que no condice con sus antiguas creencias o su concepto del "yo", lo que los fuerza a abordarse a partir de la fantasía, el corte o la metamorfosis. Blanco lo dice elocuentemente cuando afirma que, de alguna manera, "el modelo 
produjo también sus propios sujetos, sujetos cuyas identidades colectivas [...] se encuentran pulverizadas por las reglas combinatorias de la globalización y la flexibilidad de los mercados" (52). Desaparecida una época, esa época también se lleva consigo algo de las biografías (Arfuch 29), con lo cual abre la necesidad de inventar un nuevo "yo" textual acomodado a los nuevos tiempos, un "yo" que, como ponen en evidencia ciertas textualidades, a menudo se normaliza de acuerdo con las pautas de la sociabilidad neoliberal. En esta ecuación, el antiguo ser revolucionario se vuelve fetiche o cita, se rechaza, se critica, se rehúsa o es renegado bajo los signos de la resignación o el arrepentimiento.

Quiero detenerme en algunas figuras públicas de la elite política e intelectual chilena que, al construir sus subjetividades autobiográficas, tensionan la relación entre el hoy y el ayer y, de alguna manera, ponen de relieve la crisis de la izquierda en la transición y la neoliberalización de sus protagonistas. Los textos elegidos, pienso, dan cuenta de diversos gestos y tendencias que van desde el transformismo hasta la parcelación temporal del ser o incluso la fantasía. Es omnipresente en estos textos una visión autojustificadora del sujeto que apunta a la dificultad de pensar entre épocas.

A modo de advertencia, me es importante añadir que mi intención no es atacar ni criticar a las personas que son los "personajes" de esta indagación, sino atender críticamente a las configuraciones textuales que hacen de sí mismos. En el fondo, son sus textos de la memoria y son solo los textos los que fundamentalmente me interesan. Para llevar a cabo este ejercicio, he elegido a tres figuras cuyas vidas y actuar público han suscitado reacciones encontradas: Max Marambio, un exmirista (Movimiento de Izquierda Revolucionaria) convertido en un empresario y su libro Las armas de ayer (2008); Eugenio Tironi, un ex-MAPU (Movimiento de Acción Popular Unitario, un ala radicalizada de la Democracia Cristiana) y sociólogo que actualmente tiene intereses de lobbista, y su libro Chile y la ruta a la felicidad (2006); y el joven político Marco Enríquez-Ominami, sus intervenciones a través de su documental Chile, los héroes están fatigados (2002) y su libro Animales políticos: diálogos filiales (2004), este último escrito en colaboración con su padrastro, el senador Carlos Ominami.

\section{Max Marambio: el pasado como cita}

Desde el título mismo de Las armas de ayer (2008), publicado por la editorial de centro-derecha del diario La Tercera, la época de la lucha armada queda relegada al pasado. Una temporalidad en pretérito (la figura del ayer) le otorga a la época de los setenta el estatus de la cita y lo meramente anecdótico. El sujeto que narra, el exmirista Max Marambio, educado y entrenado en Cuba para importar 
la lucha armada a Chile, hijo del diputado socialista y diplomático Joel Marambio, aparece como un sujeto escindido, cuya vida actual de empresario, nunca mencionada en el libro, permanece totalmente desvinculada de su juventud de aventuras e idealismo audaz. Una y otra vez Marambio hace referencia a su otrora profunda admiración por el Che, Fidel y la aventura guerrillera, a tal punto que a veces parece estar intentando crearse un lugar para sí en aquel panteón de héroes de la izquierda: "En mi idealismo juvenil el Che era invencible y la posibilidad de estar con él servía de sostén a mis sueños revolucionarios" (51).

Con una escritura agilizada por la pluma del conocido escritor chileno Germán Marín, la autobiografía de Marambio se inicia cumpliendo al pie de la letra con el paradigma del héroe mítico detallado por Joseph Campbell en su ya clásico libro El héroe de las mil caras (1949). Marambio se va de Chile con su padre a los diecisiete años, se empeña en convertirse en guerrillero, se entrena en el monte y hasta llega a considerarse otro hijo de Fidel. Su narrativa da una impresión de los primeros años setenta como un momento de ensoñación, aventura y utopía. Al llegar a Cuba, un joven moldeable e impetuoso se baja del avión con ojos parecidos a los de los primeros cronistas de América. El entorno cubano emana, para el joven Marambio, un aire exótico de lo "real maravilloso": "Cuando se abrió la puerta del avión, sentí que me envolvía una bocanada de aire denso, como el expelido por un animal salvaje, y sucumbí al calor insólito, a la intensidad de los colores" (16). De ahí no tarda mucho en descubrir su naciente vocación de guerrillero: "En Cuba encontré mi modelo de sociedad"; "fue la pasión de la epopeya"; "aún existía el campo socialista y a nadie se le ocurría anunciar el fin de la historia"; "mi lógica era hacer lo mismo que hacía mi padre, pero con un criterio armado" $(22,24)$. Mientras progresa la lectura, vemos a Marambio ensayando ser guerrillero en simulacros de guerrilla, absorbido por la urgencia del momento, con tanto afán que teme que, si no se apura, jamás llegará la hora de subirse a su "montaña", es decir, vivir su propio momento de la gloria $(38,41)$. Instigado por un ritmo narrativo que también implica al lector en la rapidez de los sucesos, Marambio, igual que el héroe mítico de Campbell, queda transformado por sus experiencias en lo más esencial de su identidad. Su performance textual revela cómo deja atrás "su ropa de civil" para vestirse "con uniforme de verde olivo" (49). Concluido un tercio del libro, la transformación se vuelve efectiva: "Ya no era la persona de antes" (52).

Sin embargo, nada es para siempre. Si bien hasta este punto el libro ha narrado el compromiso de un chileno "consecuente" que renuncia a sus raíces burguesas para convertirse en un guerrillero radicalizado, lo que resta de Las armas de ayer no hace más que narrar el distanciamiento del narrador con respecto 
a su pasado de militante, a través de un ejercicio de revisionismo histórico y de enmarcación de su ser bajo el signo de la derrota. Así, el héroe épico formado en Cuba gradualmente traza para sí, sin querer, una nueva identidad como antihéroe de una época perdida. Tras su vuelta a Chile en 1968, Marambio se integra a la dirección del MIR, cultiva una amistad íntima con Miguel Enríquez y hasta participa (no sin cierto remordimiento en la actualidad) en la "expropiación" (es decir, el robo) de bancos. Hasta logra integrarse al Grupo de Amigos Personales de Salvador Allende (GAP), su guardia personal, lo cual permite que él establezca una vez más una relación íntima con otra figura monumental de la historia.

A la mitad del libro, un capítulo titulado "Contradicciones del MIR" abre paso a la narración de su toma de distancia con Enríquez y la dirección del MIR y pone en marcha el desenlace de su trayecto autobiográfico. Altamente crítico de cómo con el paso del tiempo el MIR llegó a parecerse más y más a los partidos políticos que pretendía criticar, Marambio no solo se distancia del grupo al que hace poco había sido adicto, sino también de Allende, siempre cuidadoso, cabe añadir, de no renunciar a su ser de "izquierda" desde un punto de vista retórico: "Así, quedé ajeno a cualquier militancia" (97). Con la muerte de Allende, se consolida su identidad de derrotado: "Ahora solo me animaba el deseo de combatir contra el abuso que tenía ante mis ojos y terminar con la mayor dignidad posible, que es el único privilegio que la vida permite a los derrotados" (114-115). Los últimos capítulos del libro tratan los diez meses que Marambio pasa escondido en la embajada de Cuba antes de lograr su pasaje al exilio en Suecia. Irónicamente, lo sacan de la embajada en "uno de los escasos Mercedes Benz que circulaban entonces" en Chile (171). Muy al final del texto, en apenas tres páginas, se narra brevemente su estancia en Suecia y su regreso a Cuba, donde finalmente se integra a Tropas Especiales. Sobre su vida post-1974, ni una palabra.

En el final de Las armas de ayer, llama la atención el afán del sujeto por normalizarse. Aunque todavía no se considera a sí mismo un neoliberal, el pacto se empieza a sellar. Cuando le ofrecen la oportunidad, el aventurero ya no quiere volver a Chile o participar de la llamada Operación Retorno, una misión clandestina de 1978 cuya meta fue ingresar a Chile miristas con instrucción militar para combatir la dictadura. Marambio, al contrario, dice pensar haber "cumplido [su] ciclo en Chile" (181). También toma distancia de sus compañeros en el exilio y carece de ganas de participar en sus discusiones políticas. Prefiere, como alternativa, una vida "normal": "Traté de distanciarme del mundo muchas veces enajenante de los exiliados y me hice el firme propósito de vivir una vida tan normal como fuera posible, en compañía de Anna" (179). Priman las referencias a la banalidad de lo cotidiano, lo que pone en evidencia cómo el 
texto de Marambio se despolitiza al compás de su ser. Una serie de detalles sin consecuencia hacen eco de su posición de derrotado. Todavía en la embajada, por ejemplo, se enloquece por la teleserie Simplemente María y le escribe cartas a la Payita (Miria Contreras Bell, la compañera de Allende), quien se encuentra en el exilio, para contarle el final. Ya en Suecia, Marambio dedica su tiempo a la culinaria, a aprender a cocinar los platos locales. De todo esto, lo que llama más la atención no son las actividades en sí, sino el hecho de que Marambio opte por narrar estas banalidades en las últimas páginas de su libro en vez de ocuparse de asuntos más serios o analíticos. Del joven guerrillero de los primeros capítulos no queda nada, solo, como Marambio dice tempranamente en el texto, "un compromiso ético que me ha acompañado el resto de la vida" (22). No se especifica, sin embargo, en qué consiste ese compromiso ético ni qué relación guarda con las armas de ayer.

Hay mucho que queda fuera del libro de Marambio. No se habla del papel que las bases jugaron en el sustento del MIR. No se habla de las razones reales que Marambio tuvo para alejarse del grupo, el cual en un momento determinado prefirió abandonar la estrategia cubana de la lucha armada y optar por una política de masas. También resulta anacrónica la actitud siempre laudatoria que Marambio mantiene hacia Allende; el narrador nunca da cuenta, por ejemplo, de las tensiones importantes que existían entre el presidente y el MIR (Paleraki). Tampoco se detiene en un análisis de las dificultades que enfrentó la Unidad Popular, ni en las complejas relaciones entre Cuba y Chile en esa época. Pero nada de esto parece ser el propósito de Marambio, quien se contenta con entregarnos una visión idealista (y un tanto megalómana) de una época pasada. Para él, es más fácil aceptar el "fin de la historia" (referenciada tempranamente en el libro) que problematizar el pensar entre épocas. Hacer esto último implicaría tomar en consideración cómo cuadra su pasado guerrillero con su vida posterior de inversionista y negociante, sus fortunas multimillonarias, su quiebre con la familia Castro, los escándalos que lo rodean, y su condena en 2011 en Cuba por "cohecho, estafa y falsificación de documentos bancarios". El Marambio real, por tanto, queda en tinieblas. Para no ser violado en la coherencia de su ser autobiográfico, el yo recurre a la fantasía, a una lectura del pasado que no da cabida al hoy aunque, paradójicamente, no se aparta nunca de cierta memoria idealizadora que el hoy ha hecho posible.

No es un detalle menor que la última frase del libro de Marambio retome el motivo de la chapa, el de las diversas identidades que el sujeto que recuerda asume en el curso de la narrativa: "También [al volver a Cuba] cambió mi nombre y nunca más volví a llamarme Ariel Fontana", su chapa del MIR (181). Marambio parece querer evitar a toda costa reconciliar sus futuras identidades con las 
chapas del pasado. Es lógico. Hacerlo implicaría que el sujeto autobiográfico, rompiendo la armonía subjetiva-textual que la memoria tanto anhela, ocupara un espacio demasiado inestable e intolerable. Por otra parte, implicaría poner en riesgo la comodidad de una subjetividad ahora enteramente normalizada y acomodada al patrón neoliberal.

\section{Eugenio Tironi: el militante arrepentido}

En un capítulo de su libro Latinamericanism after 9/11 (2011), John Beverley ofrece una clave de lectura para comprender la textura narrativa de una buena cantidad de los relatos autobiográficos que rememoran la época de la militancia y las luchas armadas. Según Beverley, un "paradigma de la desilusión" tiende a permear los relatos actuales de ciertos exmilitantes, cuyas narrativas se leen como novelas de aprendizaje en las que una "adolescencia romántica" (generosa y valiente, pero también excesiva, errada e irresponsable) da paso a una "madurez biográfica" correspondiente a la normalización del sujeto (como profesional, como padre) en el marco del nuevo régimen neoliberal (99). Este arco narrativo a menudo tiene como consecuencia un énfasis exacerbado en los aspectos negativos de la militancia (lo que se hizo mal, las equivocaciones), o en la completa renegación de ella, sin un balance crítico y sin reconocer los posibles méritos de la lucha o las continuidades históricas que seguramente existen entre las luchas revolucionarias de "entonces" y las luchas sociales de "ahora". En otras palabras, un desfase temporal resulta, por un lado, en la escisión biográfica del sujeto y, por otro, en la escisión temporal de la historia. El "antes" y el "ahora" se vuelven mutuamente exclusivos y los sujetos que recuerdan se ven plagados por un sentido de culpabilidad que los insta a arrepentirse de su apasionada juventud. El resultado, por tanto, es una doble ofuscación: primero, de los verdaderos sentidos de la historia y, segundo, de los verdaderos sentidos de una vida.

Este paradigma de la desilusión identificado por Beverley se pone elocuentemente de relieve en el caso del sociólogo, lobista, empresario y ex-MAPU Eugenio Tironi, particularmente en su libro Crónica de viaje: Chile y la ruta a la felicidad (2006), y en textualidades afines, como la entrevista "Soy un capitalista reformador" que concedió a La Tercera el 11 de agosto de 2012. Desde las primeras páginas de su libro, Tironi sabe perfectamente bien, y lo pone en evidencia, que Crónica de viaje no es solamente el recuento de la trayectoria histórica, política y social de Chile a partir de los años setenta, sino también el recuento íntimo de una subjetividad cómplice con esa trayectoria. Él mismo lo dice: "Este ensayo es, entonces, una reflexión acerca de la identidad chilena; pero envuelta en ella, 
no lo dudo, hay una reflexión sobre mi propia identidad personal" (Crónica 16). Sin embargo, su ensayo no se lee como un texto típicamente autobiográfico en el sentido de que no se centra obsesivamente en la primera persona. Durante una gran parte del libro, el "yo" que narra se oculta tras el discurso en tercera persona más característico de la sociología tradicional, solo para emerger en momentos decisivos que permiten vislumbrar las ficciones que ese "yo" teje para representarse como un ser autobiográfico íntegro, armónico y sin baches en el presente de la enunciación.

Sabemos que Tironi fue integrante del MAPU, un grupo de jóvenes demócratas cristianos que en los primeros años setenta se radicalizó y quebró sus vínculos con el partido de origen para formar un movimiento inspirado por el marxismo y que rechazaba rotundamente cualquier opción de aliarse con los partidos burgueses (Gumucio). En un blog escrito por Eduardo Aquevedo, otro ex-MAPU, el autor recuerda a Tironi como un "marxista no ortodoxo, pero marxista al fin como todos nosotros", caracterización que se confirma cuando recordamos que Tironi no solo fue MAPU, sino también integrante del MAPU-Garretón, la facción más radicalizada del movimiento nombrado por su líder Óscar Guillermo Garretón (Aquevedo). Para ir más lejos, un artículo publicado en 2001 por la revista Qué Pasa afirma que fue Tironi el que en 1973 acuñó el famoso lema "avanzar sin transar", el cual fue adoptado por quienes discrepaban con los métodos "reformistas" que Allende usaba para llevar a cabo la transformación del país (Farfán y Faúndez). Aunque las críticas a los Chicago Boys y el modelo neoliberal seguían presentes en el discurso de Tironi durante los años ochenta, es en esa misma época, ya en el exilio en París, que el sujeto inicia una ruptura con su pasado marxista. Según una tesis de Héctor Hermosilla, "Tironi, en sus viajes por Europa, comienza a acercarse a una política de alianzas que ya no privilegia la lucha insurreccional, sino más bien el diálogo y el consenso político" (122). En los primeros años ochenta estalla una crisis en el seno del MAPU respecto de su rumbo futuro, y Tironi encabeza un sector que plantea la disolución del movimiento y una movida hacia la Convergencia Socialista, la cual, a la larga, desembocaría en la llegada a La Moneda de Ricardo Lagos (Moyano Barahona 391-420).

Dado su pasado revolucionario marxista de MAPU, es curioso que ese pasado se silencie casi enteramente en Crónica de un viaje. Las referencias que hay en el libro a los primeros años setenta corresponden a la figura de Allende, que Tironi representa en su texto como un indeciso atrapado entre dos caminos y cuya muerte épica, paradójicamente, puede haber contribuido a consolidar la épica pinochetista neoliberal. En vez de revisar crítica y balanceadamente el 
periodo de la Unidad Popular, el autobiógrafo, desilusionado y arrepentido, no puede hacer más que reparar en el rotundo fracaso y la irreversible derrota: "No tengamos vergüenza; nosotros que somos lo suficientemente viejos para ser [los] contemporáneos [de Allende], sabíamos muy bien que su proyecto estaba destinado al fracaso; esperábamos otra cosa, quizás deseábamos secretamente su muerte" (Crónica 114).

En Tironi, entonces, no hay marcha atrás. Una época da paso a otra. Se funda "otra sociedad" (145). Repetidamente en su libro Tironi anuncia la muerte de las grandes ideologías y también de la política en sí. De hecho, señala que el proyecto de la dictadura de Pinochet tenía como meta principal "terminar con la política como tal", dejando que el mercado sirviera como fuente primaria de la felicidad y la recompensa de los individuos (129). Según su tesis, la guerra fría (ideológica) de su generación ahora se ha transformado en una nueva guerra fría entre las versiones europeas y estadounidenses del neoliberalismo. Al haber optado por la versión estadounidense, Tironi piensa que Chile ha perdido su rumbo histórico, y en particular su sentido de comunidad nacional (diría yo, imaginada o imaginaria); ahí radica la leve crítica que su libro ofrece al modelo. Su estancia en París, donde escribe su libro en 2006, le enseña que el capitalismo europeo es más "humano" que el estadounidense y, por tanto, cree que a Chile le haría bien retomar su cauce histórico inspirado en la socialdemocracia europea que antecedía al golpe del 73. En el fondo, su libro viene a ser una apología de la obra de la Concertación justamente porque esta logró mitigar los efectos nefastos del neoliberalismo puro estadounidense (léase, introdujo más socialdemocracia), dándole un giro hacia la "costa este", es decir, hacia una base más "demócrata" que "republicana" (según las definiciones norteamericanas), e hizo relativamente bien al construir una "democracia de masas" con mayor acceso a la educación y a la salud para los sectores menos pudientes (163). Tironi reconoce que la desigualdad social es la "gran vergüenza de Chile", pero en vez de cuestionar el modelo en su raíz, encuentra la solución en la europeización de Chile (200).

Si bien los argumentos de Tironi son altamente discutibles y sus metáforas son reductivas, no son los argumentos ni las metáforas lo que más me interesa aquí. Lo que me interesa, como vengo explicando, es la creación de su ser biográfico, textual. Y, en ese sentido, encuentro una clave de lectura en una sección del libro titulada "Sin relato" (187). Allí Tironi, citando a Richard Rorty, recuerda que "no hay una manera no mitológica, no ideológica de contar la historia de un país", lo cual da para pensar que lo mismo se podría decir de un individuo. El problema de la "revolución modernizadora" de Chile y de la Concertación, para 
Tironi, es que ambos constructos han quedado sin relato épico en la imaginación

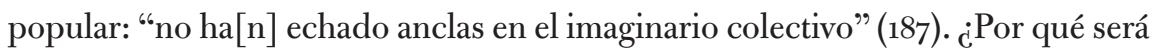
esto? Porque

la Concertación pareciera que nunca ha sentido como realmente propio lo que ella misma ha hecho: el redireccionamiento de la modernización chilena, sin quebrar la matriz incuestionablemente estadounidense que viene de la dictadura, en una orientación democrática e incluyente. Esta obra histórica [...] la Concertación la exhibe con culpa, como "lo que se pudo hacer dadas las restricciones"; nunca con orgullo, como "lo que hemos querido y logrado hacer para transformar la faz de Chile". (189)

Tironi piensa que la Concertación debe abandonar sus traumas y su narrativa culposa y defender orgullosamente su obra de veinte años, porque solo así logrará forjar una "identidad moral" que justifique su existencia (190).

Al igual que la Concertación que discute, Eugenio Tironi parece un sujeto que ha quedado "sin relato", un náufrago de la historia que narrativamente busca su norte como los dos remeros en una canoa que adornan la portada de su libro. Crónica de viaje, entonces, constituye su intento de dejar plasmada en el papel una "identidad moral", una justificación de su buen obrar como "capitalista reformador" cuando él mismo puede estar sintiendo la misma culpa que dice existir entre algunos de sus colegas de la elite concertacionista.

Entrevistado por La Tercera en 2012, Tironi afirma que "adhir[ió] al modelo económico [neoliberal] bastante tempranamente, a fines de los años 70", lo cual parece absolutamente contradictorio dado lo que sabemos de su trayectoria y lo que sus correligionarios han testimoniado respecto de él. En una entrevista del 2006, contemporánea con su libro, había renegado explícitamente de su pasado diciendo "no sentirse parte de la generación MAPU" porque él es más joven que muchos de sus colegas de aquella época y porque no hizo carrera política posteriormente ("La muerte del MAPU"). El autobiógrafo, entonces, "da la cara" en el presente porque está convencido de que hay que hacerlo. Pero al "dar la cara", queda más que claro que el sujeto tambalea en la incomodidad de su camaleonismo, consumido por la ficción de su "yo" y los silencios que esta le impone: "Soy parte de una generación de sobrevivientes, y las personas que sobreviven, muchas veces lo hacen manteniendo el silencio y tragándose los secretos de cosas que han pasado. No voy a romper esa norma ni en este ni en ningún caso" (Tironi, "Soy un capitalista"). 


\title{
Marco Enríquez-Ominami: la herencia imaginaria
}

\author{
En el fondo soy hijo del ying y el yang de la izquierda, de la \\ social democracia y de la revolución, dos estéticas que se reconocen y \\ desprecian hoy en el mundo: la revolucionaria y la reformista. \\ MARCO ENRÍQUEZ-OMINAMI
}

Marco Enríquez-Ominami (que se refiere a sí mismo como ME-O) es, sin lugar a dudas, un fenómeno de la política chilena reciente cuya vida pone de relieve nítidamente la crisis de pensar entre épocas. Hijo de dos padres - su padre biológico fue nada menos que el legendario líder asesinado del MIR, Miguel Enríquez; su padre adoptivo es el exmirista y exsenador socialista Carlos Ominami- ME-O parece ser la personificación simbólica de una tensión sin resolver entre la vigencia del legado radical de la lucha armada y la política de los consensos que ha caracterizado la transición a la democracia. Su biografía es heredera de estos dos polos y su carrera política de diputado (2006-2010) y de candidato a la presidencia (2009 y 2013) media constantemente entre ellos.

Si bien está claro que ME-O pertenece a un largo linaje de la elite política chilena, su proyecto y su estrategia han sido intentar hacer estallar esa misma elite desde adentro. Consciente del ocaso de la Concertación después de veinte años de gobierno, la candidatura de ME-O en 2009 parecía responder a un sentido generalizado de malestar y descontento en la población chilena, no solo con los partidos políticos tradicionales, sino también con un liderazgo de todos los colores que no canalizaba ni representaba sus intereses. Patricio Navia, en su libro El díscolo (2009), especula que si en algún sentido Michelle Bachelet (con su estilo de liderazgo de abajo para arriba) hizo posible la entrada en escena de un candidato como ME-O, el joven "díscolo" fue más lejos que Bachelet en términos de su afán de rupturismo, pues rompió lazos (igual que su padre adoptivo) con el Partido Socialista y con la Concertación, y se declaró "independiente" de la coalición que, paradójicamente, dio la chispa a su carrera política en primer lugar. Esto explica en gran medida cómo ME-O fue capaz de ganar un 20,14 \% de los votos en la primera ronda de las elecciones de 2009. Sin embargo, declararse "independiente" no quiere decir necesariamente adoptar un perfil más radical. Después de pasar revista al récord de ME-O en la Cámara de Diputados, Patricio Navia llega a la siguiente caracterización de la figura:

las suyas no son posturas estatistas a ultranza. De hecho, ME-O duda del Estado, porque cree profundamente en las libertades de las personas y porque teme que el Estado sea capturado por intereses particulares. Lo de ME-O es 
mucho más la convicción de un Estado fuerte que sea capaz de inducir, permitir, facilitar y garantizar la competencia. ME-O es capitalista, pero en la línea concertacionista, cree en un Estado que sea pro mercado y pro competencia más que pro empresa y pro negocios. (66)

Dado este perfil de ME-O como un neoliberal "progresista", aunque con ganas de unas reformas profundas al establishment y al sistema político, cabe preguntarse por la relación que puede haber entre una figura como ME-O y la herencia de la lucha armada representada por su padre biológico, Miguel Enríquez. Para contestar esta pregunta, se puede mirar para atrás en el tiempo, antes de que ME-O fuera diputado. En 2002, todavía trabajando para la productora Rivas y Rivas Ltda., el cineasta "independiente" Marco Enríquez-Ominami hizo el documental Chile, los héroes están fatigados, que lo posiciona claramente en la batalla entre épocas y en el que explora qué ha pasado con los sujetos del periodo revolucionario en la actualidad. El inicio del documental marca, como en los casos de Marambio y Tironi, el paso definitivo e irreversible de una época a otra, esta vez con un sentimiento que siete años más tarde se convertiría en el lema de su campaña presidencial: "Chile cambió" (nótese el uso del tiempo pretérito). Hablando de Miguel Enríquez, la voz narrativa de ME-O comenta: "Sus seguidores aún le cantan con fervor en algunos gimnasios municipales, pero sus seguidores ya no entusiasman... Chile ha cambiado. Pasó de la pobreza al crecimiento". Esta línea triunfalista, en combinación con la elección de Ricardo Lagos (que para Enríquez-Ominami marca la culminación de tres décadas de lucha socialista por llegar a La Moneda), lo conduce a abordar los destinos de una serie de excompañeros de su padre y a criticar ácidamente, no sin cierta ironía, la adaptación de estos al modelo neoliberal.

Entre los blancos de la crítica de ME-O en su documental se cuentan Óscar Guillermo Garretón, Enrique Correa, José Miguel Insulza, José Joaquín Brunner y el mismo Tironi, en el fondo un grupo de ex-MAPU que jugó un papel clave en el diseño de la transición y el forjamiento del pacto democrático con los militares. Las entrevistas con estas figuras resaltan un contraste reiterado entre el "ahora" y el "entonces", lo que demuestra un afán de la generación revolucionaria por dejar el pasado en el pasado. Un clip de Garretón, exlíder mapucista, por ejemplo, lo muestra arengando a una concentración de masas durante la época de la UP para promover la "fuerza popular"; esto se yuxtapone con la imagen diametralmente opuesta del empresario Garretón (en la actualidad) que desde la comodidad de su oficina explica que la lucha armada, a la larga, incluso en la victoria "crea sociedades que [a él] no [le] gustan". Después de catorce años vividos 
en el exilio, a Garretón lo toman preso por sus declaraciones de la juventud. En esa ocasión, Garretón, según el guión del ME-O, "se retract[a] públicamente, pidiendo perdón por sus 'confusiones revolucionarias"”. Otro guerrillero arrepentido.

Siguiendo en esa línea, varios de los entrevistados hacen referencia a la normalización de los sujetos y de la política bajo el régimen neoliberal. Para Correa, por ejemplo, las pasiones, lo afectivo, solo tienen cabida en la vida íntima de las personas y deben quedar totalmente desvinculadas de la esfera de la política, que es "terreno de la más pura y estricta operación de la razón". Tironi, por su parte (o, por lo menos, en la representación que ME-O hace de él), parece operar con una mentalidad mercantil casi fundamentalista, sin escrúpulos éticos: "Yo hago negocios, y cuando uno hace negocios no hay mención de la vida. Y cuando hago negocios, hago negocios con gente que tiene distintas historias. No me interesa cuáles son sus historias. Algunos de ellos no son ni chilenos, ni sé de dónde vienen". Brunner, en cambio, un sujeto menos extremo en sus pronunciamientos, busca legitimación de su biografía reparando, no en su ser presente, sino en una identidad histórica de izquierda (matizada, otra vez, por el tiempo pretérito) a la que dice pertenecer: "Y si por alguna razón alguien me pregunta, pues ¿tú sigues siendo de izquierda o no?, obviamente que diría que sí porque me parece que recurro legítimamente a un signo de mi identidad histórica". Esta historización de la identidad ideológica, a mi parecer, termina siendo otra forma más de compartimentar los fragmentos de una subjetividad rota.

Todas estas posturas son leídas desde afuera hacia el final del documental por la periodista y académica Faride Zerán, quien aparece afirmando que los sujetos retratados pertenecen a "una izquierda que en algún momento dejó ser izquierda y fu[e] seducid[a] por lo políticamente posible, sobre todo en el inicio de la transición". Para ella, ser de izquierda no es transar ni adaptarse a los tiempos, sino más bien constituye "un estado de ánimo, una forma de ser".

Una de las secuencias más impactantes, y altamente criticables, del documental capta una visita de ME-O a la tumba de Miguel Enríquez en el Cementerio General de Santiago. Parado ante un nicho humilde, el hijo del revolucionario caído lamenta en voz alta el ocaso de la izquierda, su cansancio y el "transformismo" que la ha asediado (Moulian 145-147). "Todos estos héroes que tú conociste", le dice a su padre, "se transformaron en unos esclavos de la eficiencia sin reparar en los costos... Me temo que tu muerte no sirvió de nada". El comentario en sí choca, pero la especulación de ME-O respecto del martirio de su padre parece mal fundamentada si tomamos en consideración el desfase temporal que opera en ella; el comentario se lanza desde un "aquí y ahora", desde un presente deshistorizado y una mirada generacional que no logran resolver las tensiones entre 
aquel pasado y el actual estado de las cosas. Para ME-O, Miguel Enríquez es una fuente de inspiración ético-moral (como lo es Allende para Marambio), pero a fin de cuentas es un mito con el que está "condenado" a vivir. Por lo tanto, ser neoliberal e hijo de un revolucionario genera una disonancia cognitiva en el sujeto que hace necesario un esfuerzo sostenido por reconciliar la leyenda de Miguel ("una cierta idea de izquierda", como dice ME-O al comienzo del documental) con la izquierda renovada que lo rodea y de la que forma parte.

Es evidente que ME-O rescata de su padre muerto cierto ímpetu ético, cierto norte que guía sus pasos y su rebeldía contra el establishment, pero es igualmente evidente que su padre biológico, del que dice no tener recuerdos fijos, al final representa una herencia imaginada. Para ME-O, Miguel es una figura problemática, una especie de vacío en su vida cuya memoria él tiene que inventar. Por lo tanto, en este caso el sujeto que recuerda hace un "uso selectivo" (Collins, Hite y Joignant 5) de la herencia de la lucha armada para, por un lado, crearse a sí mismo una subjetividad en el presente que cuadra con la proyección pública que quiere dar de sí y, por otro, para reivindicar el actuar "consecuente" de su padre adoptivo, Carlos Ominami: "Como [Miguel], Carlos sigue en la acción, sin miedo a los riesgos. Continúa al servicio de la construcción de una izquierda coherente y política". La herencia imaginada de un padre mítico al final conduce a la redención de un padre vivo. En última instancia, tanto ME-O como Ominami brillan en este documental (¿cómo podría ser de otra manera?) que, por cierto, no deja de tener su aspecto propagandístico.

Dos años después del estreno del documental, la tensión entre épocas sigue dramatizándose en el libro Animales políticos: diálogos filiales (2004), una larga conversación intergeneracional entre ME-O y su padre adoptivo. En ella, ME-O, siempre el "díscolo", juega el papel de instigador y abogado del diablo. Parece estar allí menos para elaborar sus propias ideas que para facilitar el testimonio de un hombre que admira, su padrastro. A ratos, pero siempre con cariño, adopta un tono acusatorio hacia Ominami y su generación, increpándolos por sus pecados de comisión y de omisión. La autocrítica practicada por el mismo Ominami es notable. Reiteradamente este repara en el hecho de que su generación fue severamente traumatizada y que ha quedado sin épica: "lo claro [...] es que Chile se normalizó luego de más de treinta años de mucha intensidad política, y al normalizarse perdió la épica" (Enríquez-Ominami y Ominami 176). En su estimación, por lo menos en el momento en el que se publica el libro, Chile vive tiempos de baja intensidad política, caracterizados por el pragmatismo, la eficiencia y la administración del poder. Ominami va más lejos todavía cuando confiesa que "quizás por las circunstancias históricas y por 
nuestros traumas hemos exacerbado la dimensión de la administración del poder y descuidado el cultivo de nuestras convicciones más profundas" (141). La pregunta por el futuro de Chile, por el futuro de la izquierda, entonces, queda en el aire. Partiendo del supuesto de que "el MIR ya no existe" y de que "resulta difícil reivindicar su herencia", tanto Ominami como ME-O parecen aceptar varias premisas como dadas: uno, que el mundo ha dado un vuelco hacia la derecha y, dos, que la globalización y la economía de mercado están aquí para quedarse (138). La única pregunta posible, en este contexto, entonces es " ¿cómo ser radical en ese espacio?" (139). Pero esa pregunta en sí, sin querer, cierra la conversación "entre épocas" que justamente pretende abrir, ya que no da cabida al debate sobre lo que fue esa época ni sobre lo que la motivó. Igual que en Marambio y Tironi, el pasado es pasado, y no hay marcha atrás.

\section{Reflexiones finales}

En su libro When the Romance Ended: Leaders of the Chilean Left, 19681998, la politóloga Katherine Hite elabora una taxonomía de las orientaciones cognitivas de la izquierda chilena post-Pinochet, entre las cuales encontramos categorías como "lealistas al partido", "lealistas personales" (es decir, a figuras como Allende o Enríquez), "pensadores políticos" (que pueden cambiar de ideología) y "emprendedores políticos" (pragmáticos) (20-22). Aunque acusan rasgos de varias de las categorías que Hite nombra, las figuras de la elite cuyas biografías he estudiado en este artículo cuadran plenamente con la última, la de los "emprendedores políticos": un tipo de político fundamentalmente pragmático, dispuesto a cambiar de orientación (incluso ideológica) de acuerdo con su percepción del horizonte de "lo posible" y movido por un deseo de mantener la paz y el consenso. El enfoque de los emprendedores políticos está siempre puesto en la formación de coaliciones para gobernar, en la fomentación de los acuerdos. No sorprende, entonces, que hayan sido estas figuras - los emprendedores- las que diseñaron la transición a la democracia en Chile. Tampoco sorprende que, según Hite, su discurso haya enfatizado casi religiosamente la modernización como "una nueva ideología para un Chile de futuro" (194). Pero como bien sugiere la politóloga, esta política de los consensos no es una mera elección ideológica. En última instancia, no puede ser desvinculada de los inmensos traumas que la generación revolucionaria sufrió y que los han hecho querer, aunque no en todos los casos, evitar el conflicto y la confrontación a toda costa. La confrontación ha sido aceptable, sí, pero solo en la medida en que el modelo no se cuestiona.

Autobiografías como las de Marambio, Tironi y ME-O/Carlos Ominami pueblan las librerías de Chile y hasta se venden en versiones piratas en la calle. 
Son libros que le llegan a la ciudadanía, que venden y que peligrosamente van dejando su impronta en la memoria colectiva como si fueran la historia de una época. No obstante, son textualidades que escenifican un bloqueo subjetivo-cognitivo en los sujetos recordantes, producto de los traumas sufridos, de la inercia de la historia o del recambio generacional. Por consiguiente, corren el riesgo de anublar (o anular) nuestra visión de lo que la época revolucionaria realmente fue y el verdadero legado que aquella época puede tener para el presente y el porvenir.

Es propicia la reflexión de la autora Pilar Calveiro - ella misma víctima y sobreviviente de la dictadura argentina - cuando arguye que la memoria del momento revolucionario latinoamericano requiere de un "movimiento doble": por un lado, restaurar la historicidad de lo que se recuerda, con un ojo puesto en las actitudes, las pasiones, los debates y las ideas que movieron ese momento, y por otro lado, revisitar el pasado en el presente cuestionando las potencialidades del momento revolucionario para informar las luchas políticas y sociales actuales (11). En vez de tratar las temporalidades $-\mathrm{y}$ las subjetividades a las que estas temporalidades dan origen-como desconectadas, distantes o fragmentadas, una propuesta alternativa (que ya está presente en ciertas voces críticas latinoamericanas) se preguntaría por cómo saldar cuentas honesta y éticamente entre una época y otra. Solo así se puede pensar entre épocas y no a contracorriente de ellas.

\section{Obras citadas}

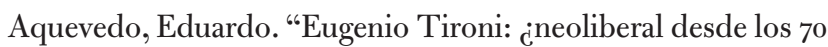
o nuevo caso de "transformismo"?". Ciencias sociales hoy. 3 de septiembre de 2012. Web. 9 de enero de 2014.

Arfuch, Leonor. Memoria y autobiografía: exploraciones en los límites. Buenos Aires: Fondo de Cultura Económica, 2013.

Beverley, John. Latinamericanism after 9/11. Durham: Duke University Press, 2011. Blanco, Fernando A. Desmemoria y perversión: privatizar lo público, mediatizar lo intimo, administrar lo privado. Santiago de Chile: Cuarto Propio, 2010.

Calveiro, Pilar. Política y/o violencia: una aproximación a la guerrilla de los años 70. Buenos Aires: Norma, 2005.

Campbell, Joseph. El héroe de las mil caras: psicoanálisis del mito. 1949. México: Fondo de Cultura Económica, 1998.

Casullo, Nicolás. Las cuestiones. Buenos Aires: Fondo de Cultura Económica, 2007.

-. Pensar entre épocas: memoria, sujetos y crítica intelectual. Buenos Aires: Norma, 2004.

Chile, los héroes están fatigados. Dir. Miguel Enríquez-Ominami. 2002. Filme. 
Collins, Cath, Katherine Hite y Alfredo Joignant, eds. The Politics of Memory in Chile: From Pinochet to Bachelet. Boulder, Colorado; Londres: First Forum Press; Lynne Rienner Publishers, 2013.

Enríquez-Ominami, Marco y Carlos Ominami. Animales políticos: diálogos filiales. Prólogo de Rafael Gumucio. Santiago de Chile: Planeta, 2004.

Farfán, Cludia y Gloria Faúndez. "MAPU. Asalto al poder". Qué Pasa 27 de mayo de 2001. Web. 9 de enero de 2014.

Gumucio, Rafael. "Chile entre dos centenarios: historia de una democracia frustrada". Polis: Revista Latinoamericana 10 (2005). Web. 9 de enero de 2014.

Hermosilla, Héctor A. "Jóvenes, rebeldes y armados: teoría, identidad y praxis del MAPU-Lautaro". Tesis de grado. Universidad de Chile, 2007. Archivo PDF.

Hite, Katherine. When the Romance Ended: Leaders of the Chilean Left, 1968-1998. Nueva York: Columbia University Press, 2000.

Marambio, Max. Las armas de ayer. Santiago de Chile: Debate; La Tercera, 2007.

Moulian, Tomás. Chile actual: anatomía de un mito.

Santiago de Chile: LOM-Arcis, 1997.

Moyano Barahona, Cristina. El MAPU durante la dictadura: saberes y prácticas políticas para una microhistoria de la renovación socialista en Chile, 1973-1989. Santiago de Chile: Universidad Alberto Hurtado, 2010.

Navia, Patricio. El díscolo: conversaciones con Marco Enríquez-Ominami. Santiago de Chile: Random House Mondadori, 2009.

Paleraki, Eugenia. "Max Marambio. Las armas de ayer. Reviewed by Eugenia Paleraki". 2008. Archivo PDF.

Richard, Nelly. "El mercado de las confesiones. Lo público y lo privado en los testimonios de Mónica Madariaga, Gladys Marín y Clara Szczaranski". El salto de Minerva: intelectuales, género y Estado en América Latina. Eds. Mabel Moraña y María Rosa Olivera-Williams. Frankfurt; Madrid: Iberoamericana; Vervuert, 2005. 299-313.

Sarlo, Beatriz. Tiempo pasado: cultura de la memoria y giro subjetivo. Una discusión. Buenos Aires: Siglo XXI, 2005.

Tironi, Eugenio. Crónica de viaje: Chile y la ruta a la felicidad. Santiago de Chile: Aguilar; El Mercurio, 2006.

-. "Eugenio Tironi: la muerte del MAPU". Emprende Futuro 17 de enero de 2006. Web. 9 de enero de 2014.

-. "Eugenio Tironi: soy un capitalista reformador". La Tercera 11 de agosto de 2012. Web. 9 de enero de 2014. 